\title{
Assessment of the conditions of the thermoplastic extrusion process in the bioactive and mechanical properties of flexible films based on starch and Brazilian pepper
}

Fakhouri, F.M. ${ }^{\text {a,b* }}{ }^{\text {; Freitas de Lima, F. }}{ }^{\text {a,d; Cardoso, C.A.L.c }}$; Martelli. S.M. ${ }^{\text {a }}$; Antunes, M. ; Mei, L.H. I. ${ }^{\text {d }}$; Yamashita, F. ; Velasco, J.I. $^{\text {b }}$

aFaculty of Engineering, Federal University of Grande Dourados. Dourados, MS, Brazil. ${ }^{\text {b} C e n t r e ~ C a t a l a ̀ ~ d e l ~ P l a ̀ s t i c, ~ U n i v e r s i t a t ~ P o l i t e ̀ c n i c a ~ d e ~ C a t a l u n y a, ~ B a r c e l o n a, ~ S p a i n . ~}$

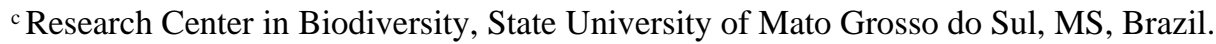

${ }^{d}$ Faculty of Chemical Engineering, State Univeristy of Campinas, SP, Brasil.

eFaculty of Food Engineering, State University of Londrina, PR, Brazil.

*E-mail of the corresponding author: farayde@gmail.com

\begin{abstract}
The objective of this work was to produce, through the thermoplastic extrusion process followed by blowing, manioc starch-based flexible films added with Brazilian pepper oil as an antioxidant and plasticizer agent, and verify if the bioactive compounds contained in the fresh pepper oil are present after the drying step of the thermoplastic extrusion. After analysis by gas chromatography-mass spectrometry volatiles compounds were identified in the films. Pepper oil also influenced the mechanichal properties of the films.These results suggest that the temperatures used in the process, kept some of the existing compounds in the Brazilian pepper essential oil adhered to the packages.
\end{abstract}

Keywords: Termoplastic extrusion, temperature, bioactivs compounds. 


\section{Introduction}

Plastic films of petrochemical origin are currently used on a large scale in food packaging, and their use is contingent upon their mechanical and barrier properties. Although chemically stable, they are not biodegradable and cause environmental impact. One of the alternatives to this problem would be the development of edible and/or biodegradable films using raw materials from renewable sources.

The bioplastics industry is still in beginning, looking to identify and exploit market niches not only for the biodegradability, recycling and / or replacement of plastics of petrochemical origin by plastics from renewable sources, also concerned about the carbon cycle and sustainability. Bioplastics are defined as materials which, containing variable percentage biopolymers, can be molded by heat and pressure. They are potential alternatives to conventional thermoplastic polymers of petrochemical origin, such as polyolefins and polyesters ${ }^{[1]}$.

Starch is a polysaccharide of plant origin, widely found in the international market, capable of forming films both by the casting technique and by the thermoplastic extrusion process. Films made with starch can also introduce additives into the packaging, such as natural antioxidant and antimicrobial agents.

The Brazilian pepper (Schinus terebinthifolius Raddi) is originally from Peru and is widely distributed throughout the Americas, including the Northeast, Southeast, South and Midwest of Brazil ${ }^{[2]}$. The fruit has healing properties attributed to the different volatile compounds that are distributed in its various organs, such as bark, leaves, flowers, fruits and seeds ${ }^{[3]}$. It is used in the food industries, as well as its essential oil in the development of pharmaceuticals and cosmetics ${ }^{[4]}$. The species has increasing pharmacological use, and is considered by popular medicine as an anti-inflammatory, antimicrobial and strong antioxidant agent ${ }^{[4,5,6]}$.

The process of extrusion allows the thermoplastification of a solid material by the application of heat and mechanical work, being the main process to obtain the bioplastics. It is a highly versatile process in which the extruder can behave as a heat exchanger due to the thermal changes occurring between the material to be extruded and the equipment ${ }^{[7]}$.

In this context, the objective of this work was to produce, through the thermoplastic extrusion process followed by blowing, manioc starch-based flexible films added with Brazilian pepper oil as an antioxidant and plasticizer agent, and verify if the bioactive compounds contained in the fresh pepper oil are present after the drying step of the thermoplastic extrusion process to obtain the biodegradable film. In parallel, we analyzed 
the mechanical properties of the films to verify the effect of the pepper oil concentration on tensile strength, elongation and elasticity of the films.

\section{Materials and Methods}

Materials: manioc starch, glycerol and brazilian pepper essential oil.

The films were produced by thermoplastic extrusion following buy blowing in single screw extruder. The range of temperature was 90 to $130 \mathrm{oC}$ and the velocitiy $35 \mathrm{rpm}$, the same condictions proposed by Fakhouri ${ }^{[8]}$. Three formulations were produced: i) manioc starch with glycerol (25\%), ii) manioc starch, glycerol (25\%) and brazilian pepper essential oil (2\%) and iii) manioc starch, glycerol (25\%) and brazilian pepper essential oil ( 3\%).

Chemical characterization by Gas Chromatography : The analyzes were performed using a gas chromatograph equipped with a mass spectrometer detector (GCMS-QP2010 Ultra, Shimadzu, Kyoto, Japan). employing a fused silica DB-5 capillary column (J \& W, 5\% de phenyl-dimethylpolysiloxane) with $30 \mathrm{~m}$ in length $\mathrm{x} 0.25 \mathrm{~mm}$ i.d., $0.25 \mu \mathrm{m}$ film thickness, under the following conditions: carrier gas helium (99.999\% and flow rate $1.0 \mathrm{~mL} \mathrm{~min}-1)$; $1 \mu \mathrm{L}$ injection volume, split ratio (1:20), with initial oven temperature of $50^{\circ} \mathrm{C}$ and heating from $50^{\circ}$ to $280^{\circ} \mathrm{C}$ at $3^{\circ} \mathrm{C}$ min- 1 . The injector temperature, transfer line and detector temperatures were $250^{\circ} \mathrm{C}$. The MS scan parameters included electron impact ionization voltage at $70 \mathrm{eV}$, a mass range of 45 to $600 \mathrm{~m} / \mathrm{z}$ and a scan interval of $0.3 \mathrm{~s}$. Temperatureprogrammed retention indices were calculated using a mixture of alkanes (C8-C30) as external references and compared with Adams ${ }^{[9]}$. The identifications were completed by comparing the mass spectra obtained in the NIST21 and WILEY229 databases and literature data ${ }^{[8]}$.

Total flavonoids quantification by Spectrophotometry: The flavonoids content was determined in the acetonic extracts of extruded S. terebinthifolius using the colorimetric method involving the reaction with aluminum chloride by Chang ${ }^{[10]}$ with adaptations for extrudates. Extracts were prepared with $100 \mathrm{~g}$ of sample added in $500 \mathrm{~mL}$ of acetone (50\% w/v), and they were kept under constant agitation (150 rpm) for five hours. The sample was filtered, and the filtrate was considered the flavonoid extract for analysis.

The extract was reacted with aluminum chloride and the readings were performed in a spectrophotometer (Biochrom - Libra S60) adjusted at $415 \mathrm{~nm}$. Quercetin solutions at nine concentrations ( 0.01 to $0.2 \mu \mathrm{g} . \mu \mathrm{L}-1$ ) were reacted with sodium aluminum chloride in order to construct a standard curve. The results were expressed as milligrams of quercetin equivalent (QE mg.100g-1 sample) using the quercetin standard curve. 
Elastic modulus, tensile strength and elongation at rupture will be determined using a texturometer (Universal testing machine Galdabini SUN 2500, TA-HDi Texture Analyser (Stable Microsystem, Surrey, England), the condictions were perfomed by ASTM methods $^{[11]}$.

\section{Results and Discussion}

After analysis by gas chromatography-mass spectrometry, fourteen volatile compounds were found in the essential oil of S. terebinthifolius (Table 1). Among these compounds, we highlight the iso-sylvestrene (34.12\%), $\alpha$-thujene $(17.13 \%)$, myrcene $(8.25 \%), \alpha$ phellandrene (6.68\%), $\beta$-longipinene (5.90\%) and sylvestrene (5.87\%). After the thermoplastic extrusion process at temperatures ranging from 90 to $130^{\circ}, 5$ volatile compounds were identified, knowingly: $\alpha$-pinene, sabinene, $\beta$-pinene, limonene and $\alpha$ copaene.

Table 1. Monoterpene and sesquiterpene chemical characterization by gas-chromatography and total flavonoids quantification by spectrophotometry of Schinus terebinthifolius Raddi oil and

\begin{tabular}{|c|c|c|c|c|c|}
\hline Compounds & $\mathbf{R} \mathbf{I}^{\mathbf{a}}$ & $\mathbf{R I}^{\mathbf{b}}$ & $\begin{array}{c}\text { Essential } \\
\text { oil }\end{array}$ & $\begin{array}{c}\text { Extruded } \\
(2 \%) \\
\end{array}$ & $\begin{array}{c}\text { Extruded } \\
(3 \%) \\
\end{array}$ \\
\hline$\alpha$-thujene & 923 & 924 & 17.13 & - & - \\
\hline$\alpha$-pinene & 939 & 939 & 1.03 & 17.43 & 18.68 \\
\hline$\alpha$-fenchene & 953 & 953 & 3.83 & - & - \\
\hline Sabinene & 975 & 976 & - & 9.54 & 10.13 \\
\hline$\beta$-pinene & 980 & 980 & 1.19 & 8.79 & 8.67 \\
\hline Myrcene & 988 & 988 & 8.25 & - & - \\
\hline$\alpha$-phellandrene & 1002 & 1002 & 6.68 & - & - \\
\hline Iso-sylvestrene & 1007 & 1007 & 34.12 & - & - \\
\hline Sylvestrene & 1025 & 1025 & 5.87 & - & - \\
\hline Limonene & 1030 & 1029 & - & 15.24 & 15.41 \\
\hline Fenchone & 1083 & 1083 & 3.69 & - & - \\
\hline$\alpha$-copaene & 1377 & 1377 & - & 9.91 & 10.12 \\
\hline$\beta$-longipinene & 1400 & 1400 & 5.90 & - & - \\
\hline Aromadendrene & 1465 & 1465 & 4.63 & - & - \\
\hline Biciclogermacrene & 1517 & 1517 & 3.21 & - & - \\
\hline$\delta$-cadinene & 1519 & 1519 & 2.29 & - & - \\
\hline Sphatulenol & 1619 & 1619 & 1.34 & - & - \\
\hline $\begin{array}{l}\text { Total flavonoids } \\
\text { (mg.100g QE) }\end{array}$ & - & - & - & 60.77 & 63.49 \\
\hline
\end{tabular}


Higher concentrations of pepper oil influenced the mechanical properties of the films, causing a significant increase in the elongation of the films and decrease of the tensile strength and elasticity (Figure 1).

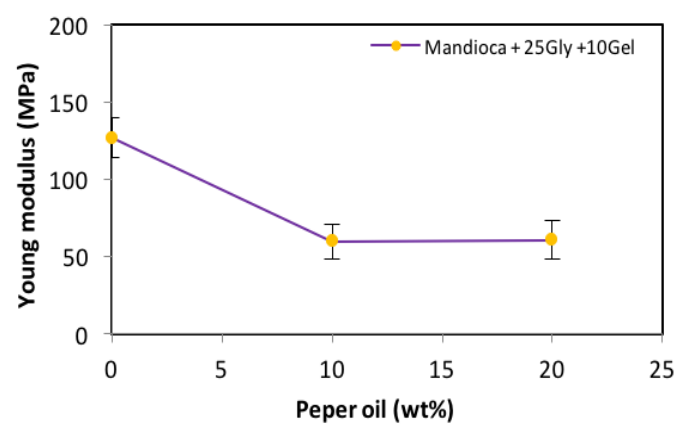

a

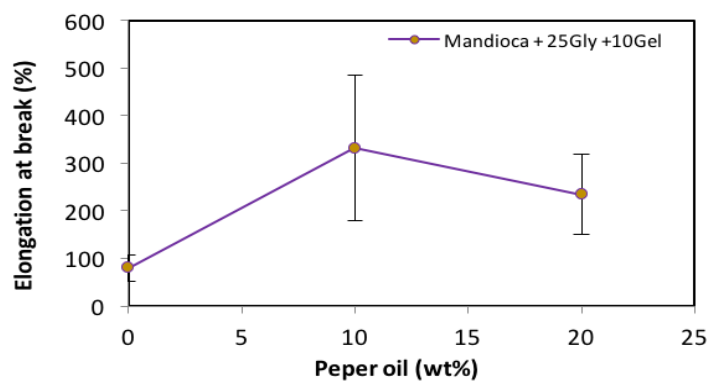

b

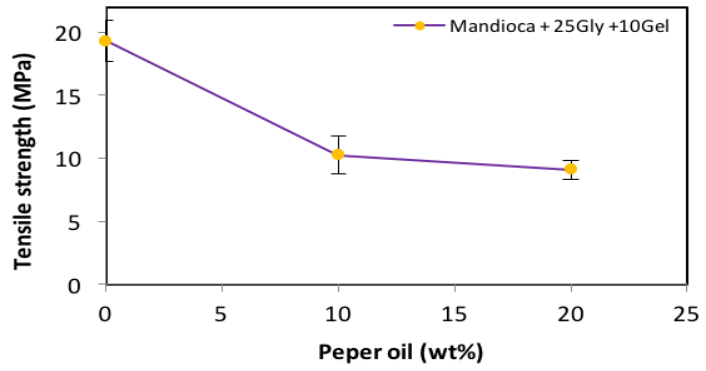

C

Figure 1. (a) Yong modulus (MPa), (b) Elogation at break (\%) and (c) Tensile Strenght (MPa) of flexible films from starch and Brazilian pepper. 


\section{Conclusions}

It was possible to obtain flexible films by manioc starch, glycerol and brazilian pepper essential oil by thermoplastic extrusion following buy blowing. After the thermoplastic extrusion process, five volatile compounds were identified, knowingly: $\alpha$-pinene, sabinene, $\beta$-pinene, limonene and $\alpha$-copaene in the flexible films. The brazilian pepper essential oil aso influenced the mechanical properties of the films.

These results suggest that the temperatures used in the thermoplastic extrusion process, although high, kept some of the existing compounds in the Brazilian pepper essential oil adhered to the packages.

\section{Acknowledgment}

Authors are grateful to TECNIOspring program.

\section{References}

[1] Queiroz, A. U. B., Collares-Queiroz, F. P., Innnovation and industrial trends in bioplastics. Polymer Reviwes, 2009, 49 (2) , 65-78.

[2] Barbosa, L. C. A., Demuner, A. J., Clemente, A. D., Paula, V. F. D., \& Ismail, F. Seasonal variation in the composition of volatile oils from Schinus terebinthifolius Raddi. Química Nova, 2007, 30(8), 1959-1965.

[3] Santos, A. C. A. D., Rossato, M., Agostini, F., Serafini, L. A., Santos, P. L. D., Molon, R. \& Moyna, P. (2009). Chemical composition of the essential oils from leaves and fruits of Schinus molle L. and Schinus terebinthifolius Raddi from Southern Brazil. Journal of Essential Oil Bearing Plants, 2009, 12(1), 16-25.

[4] Bendaoud, H., Romdhane, M., Souchard, J. P., Cazaux, S., \& Bouajila, J. Chemical composition and anticancer and antioxidant activities of Schinus molle L. and Schinus terebinthifolius Raddi berries essential oils. Journal of food science, 2010, 75, 6.

[5] Medeiros, K. C., Monteiro, J. C., Diniz, M. F., Medeiros, I. A., Silva, B. A., \& Piuvezam, M. R. Effect of the activity of the Brazilian polyherbal formulation: Eucalyptus globulus Labill, Peltodon radicans Pohl and Schinus terebinthifolius Radd in inflammatory models. Revista Brasileira de Farmacognosia, 2007, 17(1), 23-28.

[6] Formagio, A. N., Iriguchi, E. K., Roveda, L. M., Vieira, M. D. C., Cardoso, C. L., 
Fakhouri, F. M.;Freitas de Lima, F.; Cardoso, C. A. L.; Martelli. S. M., Antunes, M.; Innocentini Mei, L. H.; Yamashita, F.; Velasco, J. I.

Zarate, N. H., ... \& Kassuya, C. L. Chemical composition and anti-inflammatory activity of the essential oil of Schinus terebinthifolius Raddi (Anacardiaceae) fruits. Latin American Journal of Pharmacy, 2011, 30(8), 1555-1559.

[7] Olku, J., Linko, P. Effects of thermal processing on cereal based food systems. FoodQuality and nutricion research priorities for thermal processing, Dawney, W.K., eds London, Applied Science Publishers, 1997, 352 p.

[8] Fakhouri, F.M., Costa, D.L.M, Yamashita, F., Martelli, S. M., Jesus, R. Alganer, K., Innocentini Mei, L. H., Collares Queiroz, F.P. Comparative study of processing methods for starch/gelatin films. Carbohydrate polymers, 2013, 95, 681.

[9] Adams, R.P., Identification of essential oil components by gas chromatography/mass spectrometry. $4^{\circ} \mathrm{ed}$. Illinois USA: Allured Publishing Corporation, Carol Stream, 2007, 804 p.

[10] Chang C. C., Yang M. H., Wen H. M., \& Chern J. C. Estimation of total flavonoid content in propolis by two complementary colorimetric methods. Journal of Food and Drug Analysis, 2002,10, 178-182.

[11] Method D 882-83: Standard test methods for tensile properties of thin plastic sheeting, 1980. 